\title{
Why do we need standards?
}

Neil Loudon CEng, MICE, MCIHT

Structures Group Manager, Highways England, Bedford, UK

(neil.loudon@highwaysengland.co.uk)

In my role as a Structures Group Manager for Highways England, I often get asked why we need structures standards, and designers sometimes comment that compliance with standards inhibits innovation.

So why do structures standards exist? There are a number of threads to the answer, but primarily they all concern safety and ensuring consistency. However, to achieve this, there does need to be robust supporting processes to ensure compliance with standards and it does require appropriate personal competence (knowledge and experience) embedded throughout design, construction, inspection, operation and maintenance, and sometimes dealing with structure end-of-life.

Standards provide a baseline to allow clients, consultants, contractors, manufacturers, installers and their staff to have a common shared understanding. They can also provide the means for efficient communication, reporting and measurement, and supporting the commercial construction sector.

Standards are a fact of everyday life and they play an important societal role to ensure that there is legal compliance and to underpin a country's economy. Many early standards evolved from 'weights and measures' - they ensured that traders acted fairly and customers were not being duped. Standards allow businesses to interact and can assist with the introduction of innovation (both products and processes) by providing a baseline against which to judge the risks and benefits of new developments. Structural innovations need to fit in with the widest view of structural assets through life management, and standards help provide the means to make judgements about the acceptability of new ideas. Far from stifling innovation, the use of standards should offer an opportunity for new practices and products to be adopted. However, there must be supporting processes and documentation in place to judge the scale of the risks around the adoption of innovation.

Standards within Europe and in the UK have been developed in a spirit of professional collaboration and co-operation based on good research, applied current knowledge and practice, and through technical consensus and peer review. In the UK there is a hierarchy of standards - at the top level there are international and European standards (ISOs and Euronorms) and these are complemented by British Standards - all are design and product based. These standards are then supported by non-contradictory complementary standards such as Highways England's Design Manual for Roads and Bridges and by specifications detailed in the Manual for Contract Documents for Highway Works. These are, in turn, underpinned by a wealth of nationally developed guidance by industry-based groups and trade organisations, as well as research studies and other reports. This guidance is usually developed by steering groups drawn from the civil and structural engineering sector who support and guide authors to reflect good practice, latest knowledge or provide very detailed information about a specific technical topic.

At this guidance level there is a key role for engineers to identify and understand gaps in knowledge and, crucially, to diagnose the causes of structural failures so that lessons can be learnt and implemented to avoid recurrence. The production of guidance can assemble the evidence and provide the documentation to assist the development of future standards. Recent examples have been around the management of hidden components and safety-critical fixings. On the wider scale, tragedies such as those at Genoa, Florida and Grenfell Tower in London (UK) provide the catalyst for review and, where appropriate, to change standards and guidance.

This process of standards development can also be seen in the gestation of the second generation of Eurocodes, where the experience of engineers in using the first generation of the standards has identified gaps and a need for improved usability. The new codes will cover areas not previously addressed, such as structural assessment, the use of structural glass and improvements to the requirements for robustness. Other areas covering fibre-reinforced polymer materials and tensile membrane structures are also under development.

The process of standards development in Europe is still quite slow. This is perhaps inevitable, given the need for international consensus and managing strongly held and often diverse views. The standards must also reflect a wide range of environmental conditions, from southern Italy and Spain through to the Nordic countries. It is in this area where there is need for improvement and speeding up delivery, and future opportunities for digital collaboration and publication should assist this process. 
But what of the standards work of Highways England over the last two years? As covered in the papers in this special issue, there has been a wholesale review and republication of the Design Manual for Roads and Bridges. With over 300 documents (including 90 structures standards), this represented a huge challenge to undertake, but provided the opportunity for more regular updates in the future. We must all remember the need for professional engineering input when developing any new or revised standards, undertaking peer reviews and seeking consensus. The Highways England standards will need to be reviewed and will continue to evolve in the future, particularly in embracing issues such as climate change, sustainability, improved durability, carbon dioxide emissions and minimising waste. Achieving good, aesthetically pleasing structural designs should also be a key area.

But how do clients assure themselves that standards are being adopted and followed? Since the 1970s, Highways England (and its predecessors) has adopted the use of technical approval procedures. This has established the role of the Technical Approval Authority and the submission of Approval in Principle documentation at the start of a design process, followed by design and check certificates before construction and construction compliance certificates at the end of it. Technical approval is a well-respected process and has been widely adopted by many organisations. It was developed with the objective of clarifying design responsibility and achieving a satisfactory structural design in terms of cost, safety, the environment, buildability, maintainability and accessibility. The primary objective of technical approval is to ensure that designers adopt consistent approaches, reduce the risks of design errors and subject complex structures to independent scrutiny. The procedures are embedded in contract procedures and are adopted for new designs, maintenance operations that affect structural integrity, some temporary works and for structural assessment. Technical approval is also linked to processes for dealing with departures from standards.

Standards are with us and they guide our work to ensure that all parties in the construction process keep within safe limits. However, we do need to understand the background and the underlying principles of the standards - not to just follow them blindly. Modern standards may not deal with every design or construction scenario, but they can support innovation, through clarity of requirements and principles, and by being less prescriptive. 